\title{
Distributional Aspects of Public Rental Housing and Rent Control Policies in Spain ${ }^{1}$
}

\author{
Daniel Peña and Javier Ruiz-Castillo \\ Universidad Politécnica de Madrid and Universidad Complutense de Madrid, Pozuelo, \\ Madrid, Spain
}

\begin{abstract}
This paper studies the importance of the economic advantages and some distributional consequences generated by public and subsidized rental housing as well as rent control policies in Spain. Individual benefits are defined as the difference between the rent the protected dwellings would have in the market, minus the rent actually paid for them. The market valuation is obtained with an hedonic function estimated for the uncontrolled private sector. Data for the Madrid Metropolitan Area in 1974 show that for both policies, benefits are of considerable importance, while its distribution among beneficiaries is very unsatisfactory according to horizontal and vertical equity criteria.
\end{abstract}

\section{INTRODUCTION}

1. Background information. In Spain, like in other countries, government intervention in the housing sector takes many forms. We will concentrate only on certain aspects of two specific policies: rent control, and what we call public and subsidized housing.

On the one hand, together with the compulsory renewal clause on all leases, which dates from 1920, a 1946 law froze systematically all rentals at the level reached at the time of the first contract, following up on transitory regulations in the same vein already in effect in previous years.

A 1955 law made a dramatic policy change, allowing for an almost unrestricted bargaining on all contracts made after May 12, 1956. Present legislation, enforced since the July 1, 1964, sanctioned and extended that policy change. Lease renewals are still compulsory, but rents in new contracts are now determined by market forces; owners and renters are also allowed to include rent revision clauses subject only to annual ceilings set by the government. However, for all housing rented before 1964, the power of rent revision remained with the government. Although this power has been exercised on several occasions since that date, only moderate increases have been permitted. Therefore, we must distinguish between private rental housing occupied before or after the crucial date of 1964, which we will call,

${ }^{1}$ This is part of a wider research project, financed by the Spanish Ministerio de Economia y Comercio. The authors wish to acknowledge the help received from José Antonio Quintero, who was in charge of the computational aspects of this paper. 
respectively, pre-64 or controlled housing, and post-64 or liberalized housing.

On the other hand, the public sector promotes housing construction, either directly (public housing) or, more often, through moderate subsidies and/or substantial financial and tax incentives to the private sector (subsidized housing). In both cases, the State retains the power of fixing rents and sale prices below market levels for most housing types, according to complex procedures in whose detail we need not enter here. Finally, when public or subsidized housing is sold rather than rented, the buyer receives considerable tax benefits and has access to more favorable financial conditions than if he had acquired his home in the unsubsidized private sector.

Therefore, as a result of government intervention, we must distinguish, within the owner-occupied sector, between public, subsidized, and private housing; and within the rental sector, between public and subsidized housing on the one hand, and pre-64 and post-64 private housing on the other hand. Unfortunately, official statistics seldom classify available information according to this breakdown. Nevertheless, the following data should suffice to put into perspective the policies just summarized.

1. The growth of the Spanish housing sector during the last 30 years has been impressive, particularly from the early 1960s until 1974 when the recession hit Spain. According to census information, the housing stock grew from 6.370 million units in 1950 to an estimated 12.850 million in 1980. In 1975, 43\% of the dwellings had been built after 1960 .

2. The contribution of public policy to this process has been important, especially since the end of the 1950s. In 1980, the construction of more than four million units (or about $30 \%$ of the total) had been either subsidized or directly taken up by the public sector. Numerous and complex legislative changes, plus the intricacies of the practice, have lead to a situation in which the available statistics fail to distinguish between these two types of protection. Nevertheless, reliable estimates indicate that only 10 or $15 \%$ of the above figure can be considered public housing, while the remainder has been built by the private sector with subsidies, financial and, above all, tax incentives.

3. In recent decades we have witnessed a revolution in tenure modes. According to census data, the share of rental housing has declined from 52\% in 1950 to $30 \%$ in 1970. A recent national survey indicates that this percentage has gone down to $25 \%$ in 1980 . The decline has been also in absolute numbers: from 3.265 million in 1950 to 2.629 in 1970 .

The strict rent control up to 1964, the impediments still remaining after the liberalization in that date (compulsory renewal clause and government limits to annual rent increases), and the uncertainties created by the possibility of further legislative change, have turned the construction industry toward the owner-occupied sector. On the other hand, a public policy 
TABLE A

Percentage Distribution by Tenure and Legal Type

\begin{tabular}{|c|c|c|c|c|c|c|}
\hline & \multicolumn{2}{|c|}{ Owner occupied } & \multicolumn{2}{|c|}{ Rental } & \multirow{2}{*}{$\begin{array}{l}\text { Other } \\
\text { forms of } \\
\text { tenure }\end{array}$} & \multirow[b]{2}{*}{ Total } \\
\hline & $\begin{array}{l}\text { Public and } \\
\text { subsidized }\end{array}$ & $\begin{array}{l}\text { Private } \\
\text { sector }\end{array}$ & $\begin{array}{l}\text { Public and } \\
\text { subsidized }\end{array}$ & $\begin{array}{l}\text { Private } \\
\text { sector }\end{array}$ & & \\
\hline All of Spain ${ }^{b}$ & 15.8 & 44.4 & 8.9 & 21.9 & 9.0 & 100 \\
\hline Urban areas $a, b$ & 23.9 & 26.1 & 15.7 & 27.5 & 6.8 & 100 \\
\hline $\begin{array}{l}\text { Madrid metropolitan } \\
\operatorname{area}^{c}\end{array}$ & 20.5 & 37.7 & 8.0 & 23.5 & 10.3 & 100 \\
\hline
\end{tabular}

${ }^{a}$ Provincial capitals and municipalities of more than 50,000 inhabitants, whose stock represents $45.4 \%$ of the total.

${ }^{b}$ From a 1973-1974 Family Expenditure Survey.

${ }^{c} 1974$ data used in this article.

which concentrated on granting tax benefits to private suppliers has not worked deliberately in the direction of redressing the balance in favor of rental housing. Preferences of Spaniards for owning their home rather than renting it may have also played a role in this process.

4. It should be noted that the importance of both rental housing and the sum of subsidized and public housing has been greater in the more urbanized areas of the country, as the following data (Table A) indicate.

Unfortunately for the nonsubsidized rental sector the Family Expenditure Survey did not provide the breakdown into pre-64 (or controlled) and post-64 (or liberalized) housing. Our data for the rental sector of the Madrid Metropolitan Area (MMA hereafter) show the following percentage distribution: pre-64, 37.3\%; post-64, 37.1\%; and public and subsidized (PS housing hereafter ${ }^{2}$ ) $25.6 \%$.

2. The purpose of this paper. An assesment of these policies must begin by verifying whether they attain the central aim of providing housing at rents and prices below market levels. There is little doubt that rent controls have been effective and that public housing should be less expensive, but whether this is the case for subsidized housing is still an open question in Spain.

Assuming that the policies work - and leaving aside efficiency considerations-we are interested in the evaluation of its distributional consequences. It is almost otiose to remind ourselves of the skepticism that has always surrounded rent control as a redistributive measure among economists of different persuasions. In the Spanish case, this a priori skepticism must be extended to our second policy, because until recently the only access

\footnotetext{
${ }^{2}$ Doubts about the reliability of the breakdown of PS housing into its two components lead us to carry out most of the analysis in terms of the aggregate of public and subsidized housing.
} 
requirement to most PS housing has been the ability to pay the corresponding rent or sale price.

On the basis of a housing survey conducted in 1974 for the MMA, a previous article by one of the authors [6] explored two issues: the extent of the economic advantages generated by both policies, and some distributional problems.

As a first approximation, economic advantages for rental housing were assessed in terms of average rents and the ratio rent/family income which is a measure of the effort that households devote to the satisfaction of their housing needs. For owner-occupied housing, average prices per square meter were compared for the period 1960-1974. The basic information for the rental sector, which is the subject of the present paper, is reproduced here as an Appendix and can be summarized as follows.

Our data on average and median rent show that rents have been frozen over time when this was the policy aim, while the impact of the legislative change started in 1956 is felt only from 1960-1964 onwards. Moreover, 75\% of pre-64 households, but only $17.6 \%$ of post-64 households, devoted to rent payments less than $10 \%$ of their income.

For PS housing as a whole, average rent payments and the ratio rent/family income were also lower than in the market sector, although the differences were not as large as in the previous case. However, these averages hide strong discrepancies when one stratifies the sample by occupancy periods or type of builder: rents for PS housing occupied during the 1964-1974 period, are on average similar to those for post-64 private housing; while public housing is considerably cheaper than the different types of subsidized housing.

The second part of that paper addresses itself to the evaluation of the population breakdown into beneficiaries and nonbeneficiaries generated by those policies. For that purpose, occupants of rent-controlled housing, and renters and owners of PS housing-on the one hand-and renters and owners of uncontrolled housing-on the other hand-were classified in terms of a number of personal characteristics. For each characteristic, the comparison of the percentage distributions of those five groups and the population as a whole, lead to the following conclusions.

From the point of view of vertical equity, rent control legislation is clearly progressive: households of smaller income or family size, or whose head is a female, or an aged person, or a member of the nonworking population, or has a low educational level, are more than proportionally represented in the pre-64 housing sector. The opposite is the case for the occupants of PS housing in all tenure modes. The net effect of both policies taken together is neutral or slightly progressive.

From the point of view of horizontal equity, government intervention in the housing sector is unsatisfactory: important proportions of deserving 
social groups do not benefit from these policies. In turn, a good part of the groups which do not need special help are among the beneficiaries. In this respect, PS housing policy does considerably worse than rent control legislation.

Two objections can be raised against the descriptive work just summarized.

(1) As far as the way of measuring the economic advantages provided by these policies, the aggregate nature of data on average rents or the proportion of income devoted to rent payments in each sector may hide relevant differences at the housing unit level. ${ }^{3}$ For a more definite analysis, it is necessary to go to the microeconomic level, and treat housing services as a heterogeneous and multidimensional commodity.

(2) This distributional study does not exhaust the evaluation of public policy from the equity point of view. One would like also to apply the vertical and horizontal equity criteria to each group of beneficiaries taken on its own. Thus, for instance, one thing is to assert that the greater the proportion of poor families within a certain group of beneficiaries with respect to the population as a whole, the greater is the vertical equity of that policy. It is quite a different thing to assert that this criterion is better satisfied the greater the inverse association between the amount of individual benefits and the income level of the beneficiaries. Clearly, the same policy can be satisfactory in one case and unsatisfactory in the other.

Following Lowry et al. [3] in their study of rent control in New York City, the aim of this paper is to meet these two objections in the Spanish case. This means that we have to estimate the economic advantages of every one of the housing units under the two public programs. Lowry et al. [3] defined the benefit of a rent controlled apartment as the difference between the rent that it would achieve in the free market and the amount paid for it. In one of the first applications of the hedonic approach in urban economics, these authors predicted market rents for controlled apartments with the help of an estimated equation explaining rents for uncontrolled apartments in terms of a vector of its characteristics. Once we have a list of individual benefits, we can study (a) up to what point differences in benefits are explained by a vector of recipients' personal characteristics, and (b) the sign and degree of association between benefits and each of those personal characteristics.

The paper is organized in five sections. In Section I we justify the definition of benefit we use, and establish its relationship with other welfare measures in the context of Rosen's [5] model of demand for an indivisible and differentiated commodity. In Section II we describe the data, and

\footnotetext{
${ }^{3}$ On the other hand, differences in the proportion of income devoted to rent payments should be interpreted with caution. They surely reflect differences in the relative price of housing services. But they might also reflect systematic differences in preferences for housing services versus other goods within each of the several groups.
} 
confront a statistical problem which must be solved before applying our methodology in the rent control sector. Section III presents the distribution of benefits. Section IV contains the regression results of benefits on personal characteristics. The paper closes with some concluding comments on the equity question.

\section{THE BENEFIT CONCEPT}

In a rental housing market, transactions are purchases (or sales) of a bunch of characteristics, attributes, or traits which are acquired (or supplied) as a joint product. Under an urban economics interpretation, the key to the Rosen [5] model lies in the formulation of each agent's decision problem in characteristics space, rather than in the space of the multitude of possible varieties of that differentiated commodity we call housing services. (As a matter of fact, in order to use calculus, Rosen assumes that housing services are subject to continuous differentiation.)

If we treat housing as an indivisible commodity, each consumer maximizes his utility by choosing a quantity $x$ of an homogeneous good, which represents consumption of all other commodities, and a single dwelling unit, represented by a vector $z=\left(z_{1}, \ldots, z_{m}\right)$ whose components are the quantities of the $m$ housing attributes.

Now let us place ourselves in 1974, the year in which our data were collected. Make the consumption price equal to one, and denote by $F(z)$ the market valuation function which gives 1974 rents as a function of housing attributes. Next, consider a consumer who in 1950 rented an apartment of characteristics $z^{c}=\left(z_{1}^{c}, \ldots, z_{m}^{c}\right)$ under any of the two public programs we are studying. Denote by $R^{c}$ the monthly rent paid for this apartment in 1974. His utility level will be $u^{c}=U\left(x^{c}, z^{c}\right)$, where $x^{c}=Y-R^{c}$ and $Y$ is his monthly income in that year.

Finally, assume that this consumer is forced to rent a dwelling unit at market prices; that is, he is forced to solve the problem

$$
\operatorname{Max}_{\{x, z\}} U(x, z) \quad \text { s.t. } x+F(z)=Y .
$$

Denote the solution to that problem by $\left(x^{*}, z^{*}\right)$. His new utility level $u^{*}=U\left(x^{*}, z^{*}\right)$ will be smaller than $u^{c}$. Consequently, it seems acceptable to identify his welfare loss - or what is the same, the benefit he enjoys under the public program-with the difference $u^{c}-u^{*}$. We need a money measure of this welfare difference.

We start with two concepts of money benefits. The first is simply Hicks' compensating variation in this context.

Definition 1. Let $\left(x^{\prime}, z^{\prime}\right)$ be the solution to the problem

$$
\operatorname{Min}_{\{x, z\}} x+F(z) \quad \text { s.t. } U(x, z)=u^{c}
$$


and let $Y^{\prime}=x^{\prime}+F\left(x^{\prime}\right)$. The public program benefit to this consumer is

$$
B^{\prime}=Y^{\prime}-Y=\left(F\left(z^{\prime}\right)-R^{c}\right)+\left(x^{\prime}-x^{c}\right) .
$$

Alternatively, one can give a second definition which incorporates the restriction that consumption of $x$ remains constant.

Definition 2. Let $z^{\prime \prime}$ be the solution to the problem

$$
\operatorname{Min}_{\{z\}} x^{c}+F(z) \quad \text { s.t. } U\left(x^{c}, z\right)=u^{c}
$$

and let $Y^{\prime \prime}=x^{c}+F\left(z^{\prime \prime}\right)$. Then the constrained compensating variation is

$$
B^{\prime \prime}=Y^{\prime \prime}-Y=F\left(z^{\prime \prime}\right)-R^{c} .
$$

Unfortunately, the possibility of estimating the benefit notions just discussed runs against the following difficulty: without knowledge of the consumer's demand functions, $x^{\prime}, z^{\prime}$, or $z^{\prime \prime}$ are not observable. Consequently one is bound to accept the simplifying assumption that if the consumer is forced to go to the market, he will continue occupying a dwelling unit of characteristics $z^{c}$. In this case, the only value of $x$ which permits him to reach the utility level $u^{c}$ is $x^{c}$. Therefore, the natural extension of the previous notions becomes the definition given by Lowry et al. [3].

Definition 3. Let $\bar{Y}=x^{c}+F\left(z^{c}\right)$. Then $B=\bar{Y}-Y=F\left(z^{c}\right)-R^{c}$.

It is important to establish the relationships among these definitions.

Remark. Since $u^{*}<u^{c}$, and each successive definition incorporates an additional constraint to the previous one, we have

$$
Y<Y^{\prime} \leq Y^{\prime \prime} \leq \bar{Y} .
$$

Wherefrom, one obtains

$$
0<B^{\prime} \leq B^{\prime \prime} \leq B
$$

with

$$
B^{\prime}<B^{\prime \prime} \quad \text { if } z^{\prime} \neq z^{\prime \prime}
$$

and

$$
B^{\prime \prime}<B \quad \text { if } z^{\prime \prime} \neq z^{c} .
$$

Thus, our operational measure of the economic advantages provided by either of the public programs constitutes an upper bound for the constrained and unconstrained Hicksian compensating variations defined for our problem. 
This benefit measure is intuitively reasonable. Think for instance, of the possibility of asking the owner of an apartment rented in 1950, to make an estimate of the damage he suffers because the 1964 Spanish legislation liberalized rents only for new contracts. A plausible answer would be the difference between the rent he could obtain in today's market minus the amount he gets. The benefit we assign to that apartment is simply the counterpart of the owner's loss.

The main objection to the measurement procedure we have described is the following. In the context of Rosen's model, the estimated equation $R=\hat{F}(z)$ reflects the equilibrium of supply and demand for each housing variety. So far, we have only considered using this relationship to find a 1974 market valuation for a single dwelling under the protection of any of the two public programs. But if we want to estimate, for example, the market rent of all pre-64 housing as if, in 1974, rent controls were retroactively abolished, it is to be expected that the function $\hat{F}(\cdot)$, and hence the implicit prices for characteristics, would change drastically. However, without an econometric model of the housing market (which should probably include the owner-occupied sector) to predict the new rent function after the increase in supply, we are forced to value all dwellings under rent control, using only that sample information about post-64 housing which reflects the 1974 actual market equilibrium.

\section{THE DATA}

The data come from a 1974 housing survey of 4067 housing units in the MMA (or $0.4 \%$ of the total number for that area). There were 1240 observations for rental housing with information on all physical traits. These were broken down into 317 PS housing units, 463 pre-64 observations, and 460 post- 64 data. As explained in another paper by the authors [4], 17 of the 460 post-64 data were rejected as outliers. Columns 1 to 3 in Table 1 contain a description of housing traits for these three groups.

Before going further, we had to pay attention to a methodological problem affecting rent control housing. Suppose we accept the use of $\hat{F}(\cdot)$ to estimate 1974 market rents of controlled pre-64 housing. Is it legitimate from a statistical point of view to take those regression coefficients to predict rents of controlled dwelling units, whose traits are presumably different from those of post-64 market housing? The main difficulty is the following: while housing occupied between 1965 and 1974 can be divided into "old" or "modern" (see columns 4 and 5 in Table 1) according to whether they were built before or after 1964, all of pre-64 housing can only have been built before that date.

Clearly, the question is not whether pre-64 and post- 64 dwelling units are similar, since they are not as can be seen comparing columns 2 and 3 in 
TABLE 1

Mean values (and standard deviations) of the continuous traits

(1)

Name of variable
(2)

Pre-64
Post-64 housing

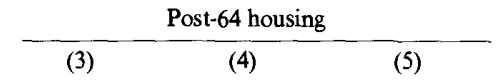

\begin{tabular}{lccccc}
\hline RENT & 3033 & $1069(1,945)$ & $4585(4,335)$ & $3649(3,445)$ & $5348(4,812)$ \\
AGE & 16.9 & $47.1(23.4)$ & $21.6(23.1)$ & $39.8(23.1)$ & $6.8(2.3)$ \\
OCUP & 9.6 & $27.7(12.9)$ & $3.5(2.2)$ & $4.0(2.5)$ & $3.2(1.9)$ \\
M2 & 70.6 & $65.0(42.6)$ & $68.2(42.7)$ & $62.5(48.5)$ & $72.9(36.7)$ \\
NFL & 6.4 & $4.2(2.1)$ & $5.1(2.8)$ & $4.0(2.5)$ & $6.1(2.8)$ \\
DET & 1.3 & $1.3(54.7)$ & $4.5(17.2)$ & $9.7(24.6)$ & $0.19(1.12)$ \\
ACC & 36.3 & $29.8(12.4)$ & $41.4(17.6)$ & $37.1(19.2)$ & $44.9(15.3)$ \\
HIGH & 0.33 & $0.32(0.81)$ & $0.06(0.88)$ & $0.26(0.93)$ & $-0.10(0.79)$ \\
OLD & 0.11 & $1.04(1.43)$ & $0.11(1.33)$ & $0.68(1.37)$ & $-3.4(0.57)$
\end{tabular}

Percentage of dummy variables

\begin{tabular}{|c|c|c|c|c|c|}
\hline AXIX & - & 18.6 & 6.7 & 15.1 & - \\
\hline CHTW & 5.7 & 6.0 & 4.1 & 5.5 & 2.9 \\
\hline LESS & 1.3 & 38.7 & 18.5 & 40.2 & 0.8 \\
\hline TWOM & 16.7 & 9.5 & 10.6 & 11.6 & 9.8 \\
\hline TELPH & 58.7 & 61.2 & 35.4 & 37.7 & 33.6 \\
\hline CHEAT & 25.2 & 8.0 & 20.5 & 10.5 & 28.7 \\
\hline GAR & 2.5 & 0.6 & 7.2 & 5.0 & 9.0 \\
\hline FURN & 12.3 & 0.6 & 15.3 & 13.6 & 16.8 \\
\hline BEXP & 30.6 & 19.4 & 18.0 & 12.6 & 22.5 \\
\hline $\begin{array}{l}\text { Number of } \\
\text { observations }\end{array}$ & 317 & 463 & 443 & 199 & 244 \\
\hline
\end{tabular}

Note. RENT = monthly rent in pesetas; $\mathrm{AGE}=$ age of building; OCUP = years of occupancy from 1974; M2 = square meters; NFL = number of floors; DET = deterioration state. The next three variables refer to the neighborhood to which housing units belong: $\mathrm{ACC}=$ accessibility index in minutes of transportation time to the CBD; HIGH = socioeconomic index; OLD = index of buildings age. AXIX = built during the 19th century; CHTW = chalet or townhouse; LESS = less than one full bathroom; TWOM = two or more bathrooms; TELPH = telephone; CHEAT = central heating; GAR = garage; FURN = furnished; BEXP $=$ building expenditures included in another concept (not necessarily the rent bill). 
Table 1. The problem is whether the influence of different traits on market rents is independent of the age of the building.

To decide this question we performed a covariance analysis. The first conclusion was that the results were sensitive to the way the variable AGE was included in the model. As we saw in Peña and Ruiz-Castillo [4], its effect was nonlinear. Therefore, the stratification of the post-64 data into old and modern subsamples affected the best specification. After some preliminary trials, we decided to represent the effect of the building age by a second-order polynomial. The resulting covariance analysis leads to the acceptance of the homogeneity hypothesis. That is to say, the effect of the different traits on market rents can be considered independent of building age.

Consequently, we felt entitled to use the best estimated model for post-64 housing to predict market rents for both pre-64 and PS housing samples. For later reference, Table 2 summarizes the regression results of such a model estimated in Peña and Ruiz-Castillo [4].

TABLE 2

Determinants of Market Rents: Regressions Results for Post-64 Housing

\begin{tabular}{|c|c|c|}
\hline Variable & Coefficient & $t$ Values \\
\hline CONSTANT & 8.13 & 24.4 \\
\hline $\mathrm{AGE}^{a}$ & -0.09 & -3.0 \\
\hline AXIX & 0.12 & 1.5 \\
\hline OCUP & -0.08 & -10.3 \\
\hline $\mathbf{M} 2^{a}$ & 0.39 & 8.4 \\
\hline $\mathrm{NFL}^{a}$ & 0.19 & 5.1 \\
\hline $\mathrm{DET}^{a}$ & -0.08 & -4.1 \\
\hline CHTW & 0.49 & 4.9 \\
\hline LESS & -0.25 & -4.3 \\
\hline TWOM & 0.19 & 2.8 \\
\hline TELPH & 0.15 & 3.6 \\
\hline CHEAT & 0.13 & 2.7 \\
\hline GAR & 0.25 & 3.5 \\
\hline FURN & 0.25 & 5.4 \\
\hline BEXP & 0.12 & 2.8 \\
\hline $\mathrm{ACC}^{a}$ & -0.41 & -5.8 \\
\hline HIGH & 0.08 & 2.9 \\
\hline OLD & -0.07 & -3.2 \\
\hline
\end{tabular}

Note. Dependent variable: logarithm of monthly rent. $R^{2}: 0.82 ; \hat{\sigma}: 0.32$. Number of observations: 443 .

${ }^{a}$ In logarithms. 


\section{COMPUTATION AND DISTRIBUTION OF THE BENEFIT VARIABLE}

The final model for the determinants of market rent can be written

$$
\ln R_{i}=\hat{\beta}_{0}+\sum_{j=1}^{17} \hat{\beta}_{j} z_{j i}, \quad i=1, \ldots, 443,
$$

where $z_{i}=\left(z_{1 i}, \ldots, z_{17 i}\right)$ is the vector of significant traits of the $i$ th dwelling, measured in the previously indicated metric.

Since the dependent variable has been logarithmically transformed, the expression $100 \cdot \hat{\beta}_{j}$ is an estimate of the percentage increase in rents due to a marginal increase in $z_{j}$. Thus, for the years of occupancy variable (OCUP), $100 \cdot 0.08=8 \%$ is interpreted as the annual rate of rent inflation during the 1965-1974 period.

The possibility of avoiding the rent inflation experienced in the market sector over that period is an advantage generated by the public programs under study. Consequently, in computing the benefit perceived we are interested in valuing all protected housing units as if they had been rented precisely in 1974; that is, making OCUP $=0$. We order the 17 explanatory variables so as to leave the OCUP variable in first place. Then, the benefit of occupying a pre-64 or a PS housing unit of characteristics $\left(z_{2 i}^{c}, \ldots, z_{17 i}^{c}\right)$ and a controlled rent $R^{c}$ is computed as follows:

$$
B_{i}=\exp \left(\hat{\beta}_{0}+\sum_{j=2}^{17} \hat{\beta} z_{j i}^{c}\right)-R^{c}
$$

Before building an explanatory model of a statistical variable, it is convenient to study its distribution to identify errors in the data, and to check, in a first approximation, if the data can be treated as homogeneous. In our case, benefits depend on housing traits by construction. Therefore, plots of benefits against the variables which have intervened in its computation also illustrate whether there are uniform variation patterns, and may serve to detect atypical values.

Four of the 463 pre-64 sample points lacked information on occupants' personal characteristics. The listing of benefits for the remaining 459 data revealed the existence of four negative values. In absolute value, two had benefits twice as large as mean benefits for the whole sample, while the other two were very small. A careful examination of the four observations lead to the conclusion that the two extreme values correspond to attractive dwellings whose rent was most likely freely bargained for under the modification of rent control legislation introduced in 1956. Since plots of benefits against 
housing traits confirmed the atypical nature of both extreme observations, we eliminated them provisionally.

In the PS housing case, 16 of the 317 data (about $5 \%$ ) yielded negative benefits, indicating that the rent regulation mechanisms may have been inefficient. On average, these 16 dwellings were of a somewhat better quality than the rest, and they certainly paid a 1974 rent ( 7762 pesetas) well above the public housing mean ( 3033 pesetas). The mean rent for the five dwellings with the greater negative benefits was 11,800 pesetas, while plots of benefits against housing traits showed that they were outside the pattern followed by the rest. However, preliminary tests indicated that the regression of benefits on personal characteristics did not improve when the five extreme data were eliminated. We decided to maintain provisionally all 317 data until more rigorous tests were performed. In any case, we deleted also six positive values-suspiciously high.

A previous work by one of the authors [6] indicated that the personal characteristics of pre-64 households varied noticeably according to the

TABLE 3

Some Characteristics of the Benefit Distribution

\begin{tabular}{|c|c|c|c|c|c|c|c|c|}
\hline & \multirow{2}{*}{$\begin{array}{l}(1) \\
\text { Mean } \\
\text { predicted } \\
\text { rent }\end{array}$} & \multirow{2}{*}{$\begin{array}{c}(2) \\
\text { Mean } \\
\text { actual } \\
\text { rent }\end{array}$} & \multicolumn{5}{|c|}{ Benefits $=(1)-(2)$} & \multirow[b]{2}{*}{$\begin{array}{l}\text { Number of } \\
\text { observations }\end{array}$} \\
\hline & & & Mean & $\begin{array}{l}\text { Standard } \\
\text { deviation }\end{array}$ & Median & Asymmetry & Kurtosis & \\
\hline \multicolumn{9}{|c|}{ PRE-64 HOUSING } \\
\hline All data & 4694 & 945 & 3749 & 2187 & 3194 & 1.60 & 3.84 & 457 \\
\hline \multicolumn{9}{|c|}{ Occupation period } \\
\hline Up to 1940 & 4688 & 782 & 3906 & 2411 & 3206 & 1.53 & 2.51 & 158 \\
\hline $1941-1956$ & 4687 & 733 & 3954 & 2206 & 3349 & 1.80 & 5.55 & 148 \\
\hline $1957-1964$ & 4706 & 1322 & 3384 & 1865 & 3186 & 1.12 & 1.63 & 151 \\
\hline \multicolumn{9}{|l|}{ PS HOUSING } \\
\hline All data & 6553 & 3033 & 3520 & 2586 & 3198 & 0.40 & 0.39 & 317 \\
\hline \multicolumn{9}{|c|}{ Occupation period } \\
\hline Up to 1954 & 7019 & 912 & 6107 & - & - & - & - & 33 \\
\hline $1955-1968$ & 6153 & 1758 & 4395 & - & - & - & - & 134 \\
\hline 1969-1974 & 6806 & 4638 & 2168 & - & - & - & - & 150 \\
\hline \multicolumn{9}{|c|}{ Type of constructor } \\
\hline Public sector & 6237 & 1540 & 4697 & 2329 & 4839 & -0.17 & 2.37 & 73 \\
\hline Private firms & 6383 & 3390 & 2993 & 2447 & 2285 & 1.06 & 1.50 & 111 \\
\hline Other private & & & & & & & & \\
\hline institutions & 6522 & 2719 & 3834 & 2787 & 3929 & -0.02 & -0.44 & 68 \\
\hline Unknown & 7196 & 4428 & 2768 & 2397 & 2424 & 0.63 & 0.82 & 65 \\
\hline
\end{tabular}


occupancy period. Also, the mean rent of PS housing units was very different when one stratified the sample by occupancy periods or type of builder. Accordingly, Table 3 shows some characteristics of the distribution of benefits for all these housing groups.

Table 3 suggests the following comments:

(1) The mean monthly benefit enjoyed by rent control housing is four times greater than its average rent payments, or $16.3 \%$ of the average monthly income for the MMA as a whole. For PS housing, the mean monthly benefit is of a comparable order of magnitude $(15.3 \%$ of the average monthly income for the MMA). A comparison of columns 1 and 3 of Table 1 shows that, on average, PS housing appears to be of superior quality to market housing along many dimensions. Consequently, our model predicts a 1974 mean market rent for PS housing (6553 pesetas) well above both mean rent actually paid (3033 pesetas), and mean rent for post-64 housing (4585 pesetas).

(2) When we stratified the rent control sample by occupancy periods, the improvement in some dimensions (age, size, deterioration state, hygienic services, and central heating) as the year of occupancy approaches 1964, appears to be offset by the worsening in some others (neighborhoods' accesibility and socioeconomic indexes). Accordingly, our model predicts about the same market rents for the three periods considered. Differences in mean benefits, which are not statistically significant, are due to differences in actual rents. For PS housing, the further away the year of occupancy, the greater the mean benefits. Moreover, units built by the public sector receive mean benefits significantly larger.

At any rate, in the subsequent regression analysis of benefits on personal characteristics, we will study the need to stratify both pre-64 and PS housing samples according to occupancy dates, as well as sign of benefits and types of constructor in the latter case.

\section{THE REGRESSION OF BENEFITS ON PERSONAL CHARACTERISTICS}

Once benefits have been computed and their distribution examined, we go on to study households' characteristics on which we have information. We have 3 continuous variables and 7 dummy variables. Table 4 gives some characteristics of the distribution of households classified by the type of housing they occupy and 10 demographic and socioeconomic variables we will be using.

It can be observed that for households in rent controlled dwellings, family income is smaller, while there is a greater incidence of families with one or more secondary nucleus, or headed by retired people, a female, a person of greater age, or of a lower educational level. On the contrary, households in PS rental housing have characteristics similar to the population as a whole. 
TABLE 4

Personal Characteristics of Households in the MMA, Classified by the Type of Housing They Occupy

\begin{tabular}{|c|c|c|c|c|}
\hline & \multicolumn{3}{|c|}{ Rental housing } & \multirow[b]{2}{*}{$\begin{array}{l}\text { Rental \& owner-occupied } \\
\text { housing in the MMA }\end{array}$} \\
\hline & Pre-64 & PS housing & Post-64 & \\
\hline \multicolumn{5}{|l|}{ Continuous variables } \\
\hline INC & 18,283 & 23,303 & 24,318 & 23,013 \\
\hline Mean & 15,675 & 15,469 & 20,330 & 17,861 \\
\hline $\begin{array}{l}\text { Standard deviation } \\
\text { Median }\end{array}$ & 15,000 & 18,000 & 18,000 & 18,000 \\
\hline \multicolumn{5}{|l|}{ PAGE } \\
\hline Mean & 57.3 & 44.4 & 39.0 & 46.7 \\
\hline Standard deviation & 13.4 & 14.6 & 13.2 & 14.3 \\
\hline Median & 57.0 & 42.0 & 36.0 & 45.0 \\
\hline \multicolumn{5}{|l|}{ SIZE } \\
\hline Mean & 3.4 & 3.8 & 3.8 & 3.7 \\
\hline Standard deviation & 1.8 & 1.6 & 1.9 & 1.7 \\
\hline Median & 3.0 & 4.0 & 4.0 & 4.0 \\
\hline \multicolumn{5}{|c|}{ Dummy variables (percentages) } \\
\hline \multicolumn{5}{|l|}{ Socioeconomic status } \\
\hline of household head & 24.8 & 8.8 & 7.4 & 12.4 \\
\hline RETTI & 31.1 & 36.3 & 41.9 & 41.3 \\
\hline LOW & 8.1 & 20.5 & 24.8 & 18.1 \\
\hline ALTA & 36.0 & 34.1 & 25.9 & 28.2 \\
\hline Remaining households & $\overline{100.0}$ & $\overline{100.0}$ & $1 \overline{100.0}$ & $1 \overline{00.0}$ \\
\hline \multicolumn{5}{|l|}{$\begin{array}{l}\text { Educational level } \\
\text { of household head }\end{array}$} \\
\hline ILPR & 42.9 & 24.2 & 28.8 & 30.6 \\
\hline ASUP & 3.9 & 6.6 & 5.9 & 5.9 \\
\hline \multirow[t]{2}{*}{ Remaining households } & 53.2 & 71.0 & 66.1 & 63.5 \\
\hline & $1 \overline{00.0}$ & $\overline{100.0}$ & $\overline{100.0}$ & $\overline{100.0}$ \\
\hline FSEX & 24.4 & 12.9 & 10.6 & 11.7 \\
\hline NUCS & 8.9 & 7.6 & 3.0 & 5.3 \\
\hline Number of observations & 459 & 317 & 460 & 3.636 \\
\hline
\end{tabular}

Note. INC = family income in pesetas per month; PAGE = age of household head; SIZE = family size; RETI = retired; LOW = low socioeconomic status; ALTA = high socioeconomic status; ILPR = illiterate or unfinished primary school; ASUP = university or professional degree; FSEX = female household head; NUCS = family with one or more secondary nucleus. 
Interesting as this information is, it is relevant to complete it by an evaluation of the horizontal and vertical equity with which benefits generated by the two public programs are distributed among the corresponding groups of beneficiaries. For that purpose, benefits in each sector are regressed on the 10 personal traits we have mentioned.

From the statistical point of view, we applied the methodology discussed in detail in Peña and Ruiz-Castillo [4]: (1) estimation of the Box-Cox transformation parameter $\lambda$ of the dependent variable; (2) study of the possibility of different sample stratification schemes; (3) careful analysis of the regression robustness in the presence of outliers; and (4) final selection of explanatory variables using the $C_{p}$ Mallows statistic.

(1) The maximum likelihood estimation of the Box-Cox parameter with 457 data was $\lambda=0.4$ for the pre-64 sample. To simplify matters we took $\lambda=0.5$, which implies taking the square root of benefits as the best transformation of the dependent variable.

The existence of large negative benefits in the PS housing sample meant that we had to add up to this variable 3761 pesetas to make all values strictly positive as required by the Box-Cox procedure. Therefore, we reduced the relative variability, pushing the estimation of the Box-Cox parameter toward one. The actual estimate was $\lambda=0.8$, well above the pre-64 figure.

(2) To decide on the need for stratification of both samples along the dimensions mentioned at the end of the previous section, we performed a covariance analysis. The results were the following. (a) The homogeneity hypothesis for the coefficients of the 10 personal variables was acceptable at the $99 \%$ confidence level when we stratified the PS housing sample according to the benefit sign and the occupancy periods, and at the $95 \%$ level in the statification of PS housing by type of builder, and of pre- 64 housing by occupancy periods. (b) The hypothesis that the occupancy period or the type of builder did not cause significant vertical displacements of the regression equations was rejected in all cases at the $99 \%$ confidence level. Therefore, in what follows, we include the following additional explanatory variables. For rent-controlled dwellings:

$$
\begin{aligned}
& 04156=1, \quad \text { if it was occupied in the 1941-1956 period; } \\
& 05764=1, \quad \text { if it was occupied in the 1957-1964 period. }
\end{aligned}
$$

For PS housing units:

$$
\begin{aligned}
05568 & =1, \quad \text { if it was occupied in the } 1955-1968 \text { period; } \\
06974 & =1, \quad \text { if it was occupied in the } 1969-1974 \text { period; } \\
P P & =1, \quad \text { if it was built by the public sector; }
\end{aligned}
$$



$\mathbf{P F}=1$, if it was built by a private firm;
PUNK $=1, \quad$ if the nature of the constructor was unknown.

(3) As far as the study of anomalous data, we began by investigating the effect of eliminating from the pre-64 sample the two extreme observations with negative benefits which we referred to in Section II. With 459 data, only 4 of the 10 personal characteristics were significant, while the coefficient of determination was 0.12 . With 457 data, the number of significant variables and the coefficient of determination raised, respectively, to 6 and 0.31 . Therefore, as previously anticipated, we felt justified in rejecting the two observations in question.

As we explained in [4], with the internal analysis of robustness of the data, we are interested in verifying: first, whether each observation is an outlier; and second, whether its influence on the estimated parameters is large or small. The first fact is judged by a $t$ statistic [1]; and the second, by the Cook $D$ statistic [2].

In the rent control sample, we isolated 14 presumably atypical observations according to $t$ values, which ranged from 4.1 to 7.7. Out of these 14 data, at least 3 have a certain influence on the estimated coefficients, judging by its $D$ values. But two of those have residuals of the opposite sign and similar $t$ values, so that it is possible that its combined effect is not large. Each of the 11 remaining observations appear to have a small influence on the estimation. The succesive elimination of 3,5 , and 14 suspicious observations, grouped according to the size of their $t$ values, did not lead to a more convincing estimation of the regression coefficients. Moreover, the estimation of the Box-Cox parameter without the 14 atypical data leads to $\lambda=0.5$, close to the value $\lambda=0.4$ with the full sample. In conclusion, we decided to reject none of the 457 observations.

Within the PS housing sample, we detected 8 data with high $t$ values and hence presumably atypical. Two of them had also a high $D$ value and a considerable influence on the estimated coefficients. After careful study of the effect of eliminating each of the 6 remaining outliers, we decided to reject a total of 4 of the 8 observations on the following grounds: with 313 data, 4 new variables become significant; the significance of 2 other variables improves; and 4 additional variables which were also significant with 317 data remain equally so.

(4) To the list of variables already mentioned, we added up the following three interaction terms with the purpose of measuring possible nonlinear effects among some personal characteristics:

$$
\begin{aligned}
\text { CAPI } & =\text { INC } / \text { SIZE } \\
\text { SEXA } & =\text { FSEX }- \text { PAGE } \\
\text { POLD } & =\text { PAGE } / \text { INC. }
\end{aligned}
$$


TABLE 5

Regression Results

\begin{tabular}{|c|c|c|c|c|}
\hline \multirow[b]{2}{*}{ Variable } & \multicolumn{2}{|c|}{ Pre-64 housing } & \multicolumn{2}{|c|}{ PS housing } \\
\hline & Coefficient & $t$ value & Coefficient & $t$ value \\
\hline INC & 0.00037 & 6.7 & - & - \\
\hline CAPI & - & - & 0.002 & 1.8 \\
\hline SIZE & -0.83 & -1.7 & - & - \\
\hline POLD & -222.6 & -2.1 & - & - \\
\hline FSEX & -16.5 & 1.9 & - & - \\
\hline SEXA & 0.25 & 1.9 & 0.7 & 2.5 \\
\hline RETI & -6.0 & -3.0 & & \\
\hline LOW & -11.4 & -6.3 & - & - \\
\hline ALTA & -5.2 & -1.8 & 48.5 & 3.2 \\
\hline ILPR & -4.5 & -3.0 & -55.5 & -4.1 \\
\hline 04156 & 2.2 & 1.9 & - & - \\
\hline 05764 & -2.7 & -1.5 & - & - \\
\hline 05568 & - & - & -77.6 & -4.3 \\
\hline 06974 & - & - & -174.4 & -9.5 \\
\hline PP & - & - & 23.1 & 1.4 \\
\hline PF & - & - & -29.0 & -2.0 \\
\hline PUNK & - & - & -56.4 & -3.5 \\
\hline Dependent variable & \multicolumn{2}{|c|}{ (Benefits $^{0.5}$} & \multicolumn{2}{|c|}{$(\text { Benefits) })^{0.7}$} \\
\hline $\mathrm{R}^{2}$ & \multicolumn{2}{|c|}{0.315} & \multicolumn{2}{|c|}{0.388} \\
\hline$\hat{\sigma}$ & \multicolumn{2}{|c|}{14.11} & \multicolumn{2}{|c|}{282.6} \\
\hline $\begin{array}{l}\text { Number of } \\
\text { observations }\end{array}$ & \multicolumn{2}{|c|}{457} & \multicolumn{2}{|c|}{313} \\
\hline
\end{tabular}

The final selection of relevant variables was made according to the Mallows $C_{p}$ statistic, which estimates the mean quadratic prediction error of the regression. The results are summarized in Table 5.

\section{CONCLUSIONS ON THE EQUITY QUESTION}

The final model indicates that, from the equity point of view, the impact of both policies among the beneficiaries is unsatisfactory.

(1) For rent control housing, personal characteristics explain only $30 \%$ of the difference in benefits. For PS housing, this proportion is $11 \%$ (the remaining $34 \%$ is explained by the period of occupancy and the type of builder). The large proportion of unexplained benefits means that the horizontal equity principle is badly fulfilled: two families of identical characteristics can receive very different benefits. 
TABLE 6

Regression Results, Including Housing Traits

\begin{tabular}{|c|c|c|c|c|}
\hline \multirow[b]{2}{*}{ Variable } & \multicolumn{2}{|c|}{ Pre-64 housing } & \multicolumn{2}{|c|}{ PS housing } \\
\hline & Coefficient & $t$ Value & Coefficient & $t$ Value \\
\hline INC & 0.0000009 & -0.03 & & \\
\hline CAPI & - & - & -0.02 & -2.7 \\
\hline SIZE & 0.3 & 1.1 & - & - \\
\hline POL & 36.9 & $(0.7)$ & - & - \\
\hline FSEX & -6.7 & $(-1.6)$ & - & - \\
\hline SEXA & 0.09 & 1.4 & 0.2 & 0.9 \\
\hline RETI & -0.06 & -0.6 & 24.5 & 1.7 \\
\hline LOW & -0.5 & -0.5 & - & - \\
\hline ALTA & -1.4 & 1.0 & 6.1 & 0.5 \\
\hline ILPR & 0.7 & 0.9 & -19.2 & -1.8 \\
\hline 04156 & -1.4 & -1.5 & - & - \\
\hline 05764 & -6.2 & 5.9 & - & 一 \\
\hline 05568 & - & - & -46.9 & -3.1 \\
\hline 06974 & - & - & -119.4 & -7.2 \\
\hline PP & - & - & 17.4 & 1.4 \\
\hline PF & - & - & -26.5 & -2.4 \\
\hline PUNK & - & - & -65.5 & -5.4 \\
\hline $\mathrm{AGE}^{a}$ & -2.1 & -2.1 & 3.7 & 0.3 \\
\hline AXIX & 4.2 & 3.6 & - & - \\
\hline $\mathrm{M} 2^{a}$ & 10.0 & 11.4 & 106.9 & 6.3 \\
\hline $\mathrm{NFL}^{a}$ & 0.8 & 0.9 & 1.8 & 0.2 \\
\hline $\mathrm{DET}^{a}$ & -2.9 & -11.5 & -32.7 & -5.4 \\
\hline CHTW & 13.0 & 8.8 & 64.6 & 2.5 \\
\hline LESS & $-8,0$ & -9.5 & -7.1 & -0.2 \\
\hline TOWM & 8.1 & 6.0 & 56.3 & 4.1 \\
\hline TELPH & 4.2 & 5.2 & 4.0 & 0.4 \\
\hline CHEAT & 2.1 & 1.4 & 0.6 & 0.05 \\
\hline GAR & 20.6 & 5.0 & 29.5 & 0.9 \\
\hline FURN & 16.4 & 4.0 & 26.1 & 1.9 \\
\hline BEXP & 5.6 & 6.4 & 40.6 & 4.6 \\
\hline $\mathrm{ACC}^{a}$ & -13.1 & -6.8 & -164.8 & -7.8 \\
\hline HIGH & 1.4 & 2.0 & 7.0 & -0.9 \\
\hline OLD & -2.2 & -5.7 & -22.0 & -3.9 \\
\hline \multicolumn{2}{|c|}{ Dependent variable } & efits) ${ }^{0.5}$ & \multicolumn{2}{|c|}{ (Benefits) $^{0.7}$} \\
\hline \multicolumn{2}{|c|}{$\mathbf{R}^{2}$} & & \multicolumn{2}{|c|}{0.73} \\
\hline$\hat{\sigma}$ & \multicolumn{2}{|c|}{6.78} & \multicolumn{2}{|c|}{65.35} \\
\hline $\begin{array}{l}\text { Number of } \\
\text { observations }\end{array}$ & \multicolumn{2}{|c|}{457} & \multicolumn{2}{|c|}{313} \\
\hline
\end{tabular}


(2) As for vertical equity, the results are not very encouraging either. In the rent control case, except for the case of the SEXA variable, the signs of all other variables are opposite of what would be desired: that the household head has a low socioeconomic or educational status, or belongs to the female sex, or the nonworking population, is associated with lower benefits. However, the greater the family income, the larger the benefits perceived. Finally, while female household heads of greater age receive greater benefits, the opposite is the case for households heads which are simultaneously old and low income recipients. In the PS housing case, the results are slightly more mixed: retired people and households headed by an older female received greater benefits. But to belong to the higher socieconomic status, or to receive a larger income per capita has also a positive premium, while belonging to the lower educational level is associated with lower benefits.

The bad distributional consequences of rent controls should not surprise us when it is understood that this legislation assigns benefits to housing units without inquiring into occupants' demographic or socioeconomic characteristics. It would only be by chance that a policy measure which in 1964 left without liberalization the controlled rents of all dwellings occupied before that date would favor, on the one hand, the most deserving groups in the population and, on the other hand, would generate benefits ten years later as a function of the characteristics of its fortunate occupants. The results are even less surprising in the case of PS housing, when one recalls that, until 1976, the economic advantages of this policy in Spain were given indiscriminantly to those willing and able to pay the rents fixed by government regulations.

As a final exercise, we estimated a model explaining benefits in terms of personal characteristics and housing traits. ${ }^{4}$ The results for both samples are summarized in Table 6 . Naturally, the goodness of fit is considerably improved. In the case of pre-64 housing, the influence of all personal characteristics on benefits becomes negligible. For PS housing, three of those variables (RETI, ILPR, and CAPI) remain significant; in regard to the vertical equity principle, the novelty is that now the greater the income per capita, the smaller are the benefits, as would be desirable. The sign and magnitude of the significant variables allow us to conclude that the size of the benefits generated by both public programs are associated to those dwellings of a better quality.

\footnotetext{
${ }^{4}$ Since benefits are in turn dependent on physical characteristics, the estimated relationship can be written as a highly nonlinear equation explaining actual rent payments as a function of housing traits and personal characteristics. We have not worked out this relationship because it is of marginal interest to the equity problem we are interested in.
} 


\section{APPENDIX}

1974 Mean Rents in the MMA (in pesetas per month)

\begin{tabular}{|c|c|c|c|c|}
\hline & $\begin{array}{c}\text { Mean monthly } \\
\text { rent }\end{array}$ & $\begin{array}{l}\text { Standard } \\
\text { deviation }\end{array}$ & Median & $\begin{array}{c}\text { Number of } \\
\text { observations }\end{array}$ \\
\hline \multicolumn{5}{|l|}{ Private housing } \\
\hline up to 1940 & 788 & 803 & 600 & 160 \\
\hline $1941-1956$ & 735 & 829 & 500 & 149 \\
\hline $1957-1960$ & 854 & 828 & 520 & 58 \\
\hline 1961-1964 & 2180 & 1939 & 900 & 96 \\
\hline $1965-1970$ & 3254 & 1447 & 2500 & 140 \\
\hline $1971-1972$ & 4150 & 2621 & 3400 & 137 \\
\hline $1973-1974$ & 5563 & 2229 & 4000 & 183 \\
\hline \multicolumn{5}{|l|}{ PS housing } \\
\hline up to 1954 & 912 & 751 & 600 & 33 \\
\hline $1955-1968$ & 1786 & 1961 & 1000 & 136 \\
\hline 1969-1974 & 4673 & 2130 & 3500 & 151 \\
\hline \multicolumn{5}{|l|}{ PS housing } \\
\hline Public sector & 1540 & 2921 & 600 & 74 \\
\hline Private firms & 3390 & 2468 & 3000 & 112 \\
\hline $\begin{array}{l}\text { Other private } \\
\text { institutions }\end{array}$ & 2718 & 3022 & 1900 & 69 \\
\hline Unknown & 4428 & 3373 & $3500^{*}$ & 65 \\
\hline Pre-64 housing & 1068 & 1275 & 500 & 463 \\
\hline PS housing & 3078 & 1756 & 2600 & 320 \\
\hline Post-64 housing & 4439 & 1114 & 3500 & 460 \\
\hline
\end{tabular}

Percentage Distribution of the Quotient Housing Rent/Family Income

\begin{tabular}{lcccccccc}
\hline & $\begin{array}{c}\text { Less than } \\
0.10\end{array}$ & $0.10-0.14$ & $0.15-0.19$ & $0.20-0.24$ & $0.25-0.29$ & $0.30-0.34$ & $\begin{array}{c}0.35 \text { or } \\
\text { more }\end{array}$ & Total \\
\hline Pre-64 & 74.9 & 8.9 & 7.5 & 2.8 & 2.4 & 1.5 & 2.0 & 100.0 \\
PS housing & 43.5 & 13.9 & 16.7 & 10.1 & 7.3 & 3.5 & 5.0 & 100.0 \\
Post-64 & 17.6 & 22.2 & 18.3 & 13.7 & 8.7 & 5.2 & 14.3 & 100.0 \\
\hline
\end{tabular}




\section{REFERENCES}

1. V. Barnett and T. Lewis, "Outliers in Statistical Data," Wiley, New York (1978).

2. R. D. Cook, Detection of Influential Observations in Linear-Regression, Technometrics, 19, 15-18 (1977).

3. I. S. Lowry, J. de Salvo, and B. M. Woodfill, "Rental Housing in New York City II: The Demand for Shelter," The New York City Rand Institute, New York (1971).

4. D. Peña and J. Ruiz-Castillo, Robust Methods of Building Linear Regression Models. An Application to the Housing Sector, $J$. of Business and Economic Statistics, 2, 10-20 (1984).

5. S. Rosen, Hedonic Prices and Implicit Markets: Product Differentiation in Pure Competition, J. Pol. Econ., 82, 34-55 (1974).

6. J. Ruiz-Castillo, La intervención del Estado en el Area Metropolitana de Madrid: Una primera aproximación, ICE, 585 (1982). 